\title{
Incidence of anemia in type 2 diabetic mellitus and its prognostic index
}

\author{
S. Periasamy ${ }^{1}$, Adhin Antony Xavier ${ }^{2}$, R. Gowtham ${ }^{3}$ \\ ${ }^{1}$ Dr S. Periasamy, Reader, Department of General Medicine, Rajah Muthiah Medical College Hospital, Chidambaram, \\ Tamil Nadu, India, ${ }^{2}$ Adhin Antony Xavier, Pharm. D. (Internship), ${ }^{3}$ R.Gowtham, Pharm. D. (Internship). Both affiliated \\ with Department of Pharmacy Practice, Rajah Muthiah Medical College Hospital, Chidambaram, Tamil Nadu, India.
}

Address for correspondence: Dr S. Periasamy, Email: prperiasamy53@gmail.com

\begin{abstract}
Objective: To identify the incidence of anemia in type 2 diabetic mellitus in a rural population and its prognostic value. Methodology: This is prospective observational study conducted at RMMCH, Chidambaram; the study comprises of 250 patients diagnosed with type 2 diabetic mellitus. Age of greater than 18 years, Risk factor such us hypertension and CAD were included in the study. Age of less than 18 years, anemia due to chronic blood loss, anemia due to other secondary causes and patient on treatment for anemia is excluded from the study. In patients with diabetic mellitus, HbA1c, Complete Blood Picture, Smear study, were done after obtaining consent detail from patients. Result: In the present study out of 250 populations females was dominated by 160/250(64\%) with mean age group of $60 \pm 13$ were mean duration of diabetes being $4.1 \pm 3$ years and mean hemoglobin level was $11.3 \pm 2 \%$, the comorbid condition such us CAD and Hypertension was present in 90 and 110 patients respectively. Mean HbA1c value was 8.4 \pm 2.1 . Normocytic Normochromic anemia was present in $25 \%$ of anemic patients; Microcytic Hypochromic anemia was found in $35 \%$, Macrocytic Hyperchromic is $32 \%$ and Dimorphic anemia was present in $8 \%$. Conclusion: Anemia is present in $74 \%$ of the study population which point towards the need of hematological evaluations and care needed for the diabetic patients for better outcome in rural population.
\end{abstract}

Key words: Type 2 Diabetic Mellitus, Anemia, HbA1c.

\section{Introduction}

Diabetes mellitus (DM) is a metabolic disorder of great impact worldwide. The diabetes affects about $7 \%$ of the population worldwide [1]. The prevalence of diabetes among adults in the southern states of India has been reported as being $18.6 \%$ in urban populations and approximately $10 \%$ in rural populations [2, 3]. With the prevalence rate is increasing in the younger age groups $[4,5]$. The long term complications of diabetes can be expected to occur during their productive years causing severe economic and social burden [6]. The increasing prevalence of type 2 diabetes mellitus has become a major public health concern. The diabetic patient number has been increasing due to population and urbanization growth, increase in the prevalence of obesity and sedentary lifestyle, and the longer survival of patients with DM [7]. Several studies suggest that anemia is twice as common in diabetics compared with

Manuscript received $24^{\text {th }}$ May 2016

Reviewed: $4^{\text {th }}$ June 2016

Author Corrected: $15^{\text {th }}$ June 2016

Accepted for Publication $29^{\text {th }}$ June 2016 non-diabetics [8]. Despite these facts, anemia is unrecognized in $25 \%$ of the diabetic patients. [9] Anemia also develops earlier and is more severe in patients with diabetes than in patients with renal impairment from other causes [10]. Recent studies have linked anemia with relatively low serum erythropoietin in persons with either type 1 or type 2 diabetes, even without advanced kidney disease or overt uremia [11]. The etiology of anemia in diabetes is multifactorial and includes inflammation, nutritional deficiencies, concomitant autoimmune diseases, drugs, and hormonal changes in addition to kidney disease [9]. Anemia is found to contribute to the development and progression of micro- and macro-vascular complications of diabetes, which has a negative impact on the quality of life and an additional burden on the health of the patients. [10, 12] There for it is important to diagnose and treat anemia in diabetic mellitus patients. This study aimed to determine the prevalence of anemia in type 2 diabetics in relation to the diabetic mellitus status. 


\section{Methodology}

This is prospective observational study conducted at RMMCH, Chidambaram; the study was carried out during the period of 3 months from February 2016 to May 2016, the study comprises of 250 patients with type 2 diabetic mellitus. All patients admitted with diabetic mellitus aged more than 18 years of both genders were included in the study. Risk factor such us hypertension and CAD were also included. Age of less than 18 years, anemia due to chronic blood loss and anemia due to other secondary causes is excluded from the study. The demographic data such as Name, Age, Sex, duration of Diabetes, HbA1c, Complete Blood Picture, Smear study, were done. Anemia was diagnosed based on WHO criteria; the data obtained was analyzed using statistical tool SPSS; version 16, mean and standard deviation were calculated from the collected data's.

\section{Result}

A total of 250 patients with diabetes were included (90 males and 160 females) in the study, out of that 185 were found to be anemic. Mean age was $60 \pm 13$ were Mean duration of diabetes being $4.1 \pm 3$ years and Mean $\mathrm{Hb}$ was $11.3 \pm 2 \%$ with unsatisfactory glycemic control in $74 \%$ of diabetics. The comorbid conditions such us CAD and Hypertension was present in 90 (70males and 20 females) and 110 (65 males and 45 females) patients respectively. Mean HbA1c value was $8.4 \pm 2.1$. The prevalence of anemia was significantly higher with $74 \%$ (185/250); which was $36 \%(90 / 250)$ in men and $38 \%(95 / 250)$ in women. Among these, Normocytic Normochromic anemia was present in $25 \%$ of anemia, Microcytic hypochromic anemia was found in 35\%, Macrocytic Hyperchromic anemia was found in 32\% and Dimorphic anemia was present in $8 \%$ respectively. The hemoglobin level was found to be less than $7 \mathrm{~g} / \mathrm{dl}$ for 16 male \& 20 female patient and more than $13 \mathrm{~g} / \mathrm{dl}$ was observed in 37 (17 male and 20 female). Highest number of population of 78 (26 males and 52 females) was seen in the range between $9-11 \mathrm{~g} / \mathrm{dl}$.

\section{Table-1}

\begin{tabular}{|c|c|c|c|c|c|c|c|c|c|c|c|c|c|c|c|c|c|c|c|c|c|c|c|}
\hline \multirow{3}{*}{$\begin{array}{l}\text { Age } \\
\text { group }\end{array}$} & \multicolumn{10}{|c|}{ HbA1c } & \multicolumn{10}{|c|}{ Hemoglobin } & \multicolumn{3}{|c|}{$\begin{array}{c}\text { Duration of } \\
\text { DM }\end{array}$} \\
\hline & \multicolumn{2}{|c|}{$<6$} & \multicolumn{2}{|c|}{$6-7$} & \multicolumn{2}{|c|}{$7-8$} & \multicolumn{2}{|c|}{$8-9$} & \multicolumn{2}{|c|}{$>9$} & \multicolumn{2}{|c|}{$<7$} & \multicolumn{2}{|c|}{$7-9$} & \multicolumn{2}{|c|}{$9-11$} & \multicolumn{2}{|c|}{ 11-13 } & \multicolumn{2}{|c|}{$>13$} & $<5$ & $5-10$ & $>10$ \\
\hline & $\mathbf{M}$ & $\mathbf{F}$ & $\mathbf{M}$ & $\mathbf{F}$ & $\mathbf{M}$ & $\mathbf{F}$ & $\mathbf{M}$ & $\mathbf{F}$ & $\mathbf{M}$ & $\mathbf{F}$ & $\mathbf{M}$ & $\mathbf{F}$ & $\mathbf{M}$ & $\mathbf{F}$ & $\mathbf{M}$ & $\mathbf{F}$ & $\mathbf{M}$ & $\mathbf{F}$ & $\mathbf{M}$ & $\mathbf{F}$ & years & years & years \\
\hline $21-30$ & 1 & 0 & 1 & 0 & 0 & 0 & 2 & 0 & 0 & 0 & 1 & 0 & 0 & 0 & 2 & 0 & 1 & 0 & 0 & 0 & 4 & 0 & 0 \\
\hline $31-40$ & 0 & 0 & 2 & 4 & 2 & 7 & 4 & 4 & 3 & 4 & 1 & 4 & 1 & 6 & 4 & 4 & 2 & 1 & 3 & 4 & 14 & 10 & 6 \\
\hline $41-50$ & 0 & 0 & 6 & 3 & 5 & 6 & 5 & 12 & 2 & 6 & 2 & 3 & 1 & 6 & 4 & 9 & 5 & 6 & 2 & 3 & 18 & 12 & 11 \\
\hline $51-60$ & 0 & 0 & 6 & 6 & 6 & 9 & 9 & 25 & 5 & 11 & 5 & 4 & 5 & 9 & 7 & 18 & 4 & 14 & 5 & 6 & 11 & 31 & 35 \\
\hline $61-70$ & 0 & 0 & 3 & 3 & 4 & 6 & 9 & 18 & 4 & 9 & 3 & 2 & 3 & 6 & 7 & 12 & 3 & 12 & 4 & 4 & 14 & 18 & 24 \\
\hline$>70$ & 0 & 0 & 5 & 2 & 2 & 5 & 5 & 13 & 3 & 7 & 4 & 7 & 2 & 5 & 2 & 9 & 4 & 8 & 3 & 3 & 9 & 14 & 19 \\
\hline
\end{tabular}

\section{Discussions}

A study conducted by Nadia et al. found anemia in diabetic mellitus patients is comparatively higher in females $(26 \%)$ than males $(10 \%)[13]$ where as in our study the incidence of anemia in diabetic mellitus was $38 \%$ in females and $36 \%$ in male. The mean duration of diabetic mellitus is 4 years in our study; where as in Nadia et al the mean duration is 7 years [13] In our study Normocytic Normochromic anemia is found to be $25 \%$, Microcytic Hypochromic anemia is $35 \%$ and
Macrocytic Hyperchromic anemia is $12 \%$ where study conducted by Nadia et al shows $59.8 \%$ of Normocytic and $37.8 \%$ of Microcytic anemia respectively. Travest et al suggest that anemia is prevalent in elderly diabetics. [14] similar pattern was seen in our study where age group between 51-60 and 61-70 have higher incidence of anemia and quarter of them remain undiagnosed. Most of the patients belong to older age group with long duration of Diabetic mellitus that could 
be possible additional contribution factor for unexplained anemia. Polypharmacy is most common among diabetic patients which may contribute to anemia directly or indirectly. Marthias et al found ACE inhibitors and ARB to be associated with reversible decrease in hemoglobin concentration in diabetics [15]. Our study shows that the comorbid conditions such us CAD and Hypertension was present in 90 (70males and 20 females) and 110 (65 males and 45 females) patients respectively which is a contributing factor to polypharmacy and further as risk factor for anemia where the same conclusion was found in study conducted by Dousampanis et al [16].

Several trials conducted of treating anemia in diabetics suggest that correction of anemia leads to improved quality of life in diabetic patients [17] were same scenario was seen in our Study. Anemia is frequently seen in diabetes and very often remain undiagnosed, WHO reports global prevalence of anemia in general population to be $24.8 \%$ (12.7 in males and 30.2 in females).[18]. With respect to the global prevalence the greatest absolute increase in the number of people with diabetes will be in India with a projected estimate of 366 million in the year 2030 from 171 million in 2000 [19].

Another chronic condition which affects the quality of life is anemia. The occurrence of anemia in diabetics was earlier attributed to renal pathology but studies have shown that anemia develops earlier in patients with diabetes when compared to patients with renal involvement due to other causes [20]. Observational studies also indicate that low hemoglobin levels in diabetics may increase risk for progression of kidney disease and cardiovascular morbidity and mortality $[21,22]$.

\section{Conclusion}

Our study shows 185 patients out of 250 were anemic; which accounts $74 \%$ of the total population which points toward the need for hematological screening in all diabetics presenting to hospital for better result outcome and prognosis.

\section{Limitation of the Study}

1. This study is conducted in rural population where most of the patients are from lower socioeconomic class, hence other care for anemia to be rule out.

2. Anemia due to secondary causes was not examined in detail.
Funding: Nil, Conflict of interest: None initiated, Permission from IRB: Yes

\section{Bibliography}

1. P. F. Pereira, R. D. C. G. Alfenas, and R. M. breast feeding A. Ara'ujo influence the risk of developing diabetes mellitus in Jornal Pediatria children, vol. 90, no. 1, pp. 7-15, 2014.

2. Ramachandran A, Snehalatha C. Current scenario of diabetes in India. J Diabetes. 2009 Mar;1(1): 18-28. doi: 0.1111/ j. 1753-0407. 2008. 00004. x. Epub 2008 Dec 17.

3. Ramachandran A, Das AK, Josh SR, Yajnik CS, Shah S, Prasanna Kumar KM. Current status of diabetes in india and need for novel therapeutic agents. JAPI. 2010 June; 58( $\sup 3): 7-9$.

4. Ramachandran A, Snehalatha C, Kapur A, Vijay V, Mohan V, Das AK, Rao PV, Yajnik CS, Prasanna Kumar KM, Nair JD; Diabetes Epidemiology Study Group in India (DESI). High prevalence of diabetes and impaired glucose tolerance in India: National Urban Diabetes Survey. Diabetologia. 2001 Sep;44(9):1094101.

5. Mohan V, Sandeep S, Deepa R, Shah B, Varghese C. Epidemiology of type 2 diabetes: Indian scenario. Indian J Med Res. 2007 Mar;125(3):217-30.

6. Mohan V, Deepa R. Prevalence of diabetes and metabolic syndrome among Asians. International Journal of Diabetes in Developing Countries. 2010 Oct -Dec;30(4):173-5.

7.Brasil Minist'erio da Sa'ude, Diretrizes da Sociedade Brasileira de Diabetes 2013- 2014, AC Farmac^utica, 2014.

8.Wright JA, Oddy MJ, Richards T. Presence and characterisation of anaemia in diabetic foot ulceration. Anemia. 2014;2014:104214. doi: 10.1155/2014/104214. Epub 2014 Jul 23.

9. Abate A, Birhan W, Alemu A. Association of anemia and renal function test among diabetes mellitus patients attending Fenote Selam Hospital, West Gojam, Northwest Ethiopia: a cross sectional study. BMC Hematol. 2013 May 7;13(1):6. doi: 10.1186/2052-183913-6. 
10. Thomas MC, Cooper ME, Rossing K, Parving HH. Anaemia in diabetes: Is there a rationale to TREAT? Diabetologia. 2006 Jun;49 (6) : 1151-7. Epub 2006 Apr 4.

11. El-Achkar TM, Ohmit SE, McCullough PA, Crook ED, Brown WW, Grimm R, Bakris GL, Keane WF, Flack JM; Kidney Early Evaluation Program. Higher prevalence of anemia with diabetes mellitus in moderate kidney insufficiency: The Kidney Early Evaluation Program. Kidney Int. 2005 Apr;67(4):1483-8.

12. New JP, Aung T, Baker PG, Yongsheng G, Pylypczuk R, Houghton J, Rudenski A, New RP, Hegarty J, Gibson JM, O'Donoghue DJ, Buchan IE. The high prevalence of unrecognized anaemia in patients with diabetes and chronic kidney disease: a populationbased study. Diabet Med. 2008 May; 25 (5) : 564-9. doi: 10.1111 /j. 1464 - 5491. 2008. 02424 . x.

13. Nadia Shams, M.H. Osmani. Newly Diagnosed Anemia in Admitted Diabetics, Frequency, Etiology and Associated Factors. Journal of the College of Physicians and Surgeons Pakistan 2015, Vol. 25 (4): 242-246.

14. Trevest K, Treadway H, Hawkins-van der Cingel G, Bailey C, Abdelhafiz AH. Prevalence and determinants of anemia in older people with diabetes attending an outpatient clinic: a cross-sectional audit. Clin Diabetes. 2014 Oct; 32 (4):158-62. doi: 10.2337 / diaclin. 32.4. 158.

15. Marathias KP, Agroyannis B, Mavromoustakos T, Matsoukas J, Vlahakos DV. Hematocrit-lowering effect following inactivation of renin-angiotensin system with angiotensin converting enzyme inhibitors and angiotensin receptor blockers. Curr Top Med Chem. 2004;4(4):483-6.
16. Dousdampanis $\mathrm{P}$, Trigka $\mathrm{K}$, Fourtounas $\mathrm{C}$. Prevalence of anemia in patients with type II diabetes and mild to moderate chronic kidney disease and the impact of anti-RAS medications. Saudi J Kidney Dis Transpl. 2014 May;25(3):552-7.

17. Silverberg DS, Wexler D, Blum M, Tchebiner JZ, Sheps D, Keren G, Schwartz D, Baruch R, Yachnin T, Shaked M, Schwartz I, Steinbruch S, Iaina A. The effect of correction of anaemia in diabetics and non-diabetics with severe resistant congestive heart failure and chronic renal failure by subcutaneous erythropoietin and intravenous iron. Nephrol Dial Transplant. 2003 Jan;18(1):141-6.

18. World Health Organization. Haemoglobin concentrations for the diagnosis of anaemia and assessment of severity. Geneva: world health organization; 2010.

19. Wild S, Roglic G, Green A, Sicree R, King H. Global prevalence of diabetes: estimates for the year 2000 and projections for 2030. Diabetes Care. 2004 May;27(5):1047-53.

20. Thomas M, Tsalamandris C, MacIsaac R, Jerums G. Anaemia in diabetes: an emerging complication of microvascular disease. Curr Diabetes Rev. 2005 Feb; 1(1):107-26.

21. Osama El, MinshawyEman El. Anemia and Kidney Dysfunction in Type 2 Diabetic Patients. Nephrourology monthly. 2010 Sep; 02(04):543-52.

22. Cristoph H. Anaemia in Patients with Diabetic Nephropathy - Prevalence, Causes and Clinical Consequences . European Cardiovascular Disease 2007.

\section{How to cite this article?}

S. Periasamy, Adhin Antony Xavier, R. Gowtham. Incidence of anemia in type 2 diabetic mellitus and its prognostic index. Int J Med Res Rev 2016;4 (7):1239-1242.doi:10.17511/ijmrr.2016.i07.28. 